\title{
De un rey sabio e ilustrado: Los inicios de los estudios alfonsíes en el siglo XVIII
}

Of a Wise and Enlightened King: The Beginnings of Alphonsine Studies in Eighteenth-Century

Johan Puigdengolas

Universidad Toulouse Jean Jaurès

CESXVIII, núm. 30 (2020), págs. 517-539

DOI: https://doi.org/10.17811/cesxviii.30.2020.517-539

ISSN: 1131-9879

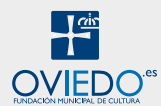




\title{
Resumen
}

Los estudios alfonsíes empezaron a constituirse en el siglo XVIII gracias a la empresa de investigación y comentario de los fondos antiguos de España. En el presente estudio nos interesaremos por la aportación de los intelectuales dieciochescos al conocimiento de la vida y de la obra de Alfonso X el Sabio. Fascinados por los textos medievales y herederos de tradiciones historiográficas que empezaron a poner en tela de juicio, los ilustrados contribuyeron a una mejor aprehensión del corpus alfonsí gracias a sus descubrimientos y preocupaciones intelectuales. A través del ejemplo de la recepción del Setenario, veremos en qué aspectos renovaron la imagen del soberano y qué métodos emplearon para estudiar sus producciones escritas.

Palabras clave

Alfonso X el Sabio, Recepción, Setenario, Edad Media, Historia intelectual.

\begin{abstract}
Alphonsine studies started to take form in the eighteenth-century thanks to the process of investigation and commentary of the antique Spanish collections. In the present essay, we will study the contributions of the eighteenth-century intellectuals to the knowledge of Alfonso X the Wise's works. Fascinated by medieval texts, heirs to historiographical traditions that they had just started to question, the ilustrados contributed to a better apprehension of the alphonsine corpus thanks to their discoveries and intellectual preoccupations. Through the example of the Setenario reception, we will see in which aspects they renewed the image of the monarch and which methods were used to study his written works.
\end{abstract}

KeY Words

Alfonso X the Wise, Reception, Setenario, Middle Ages, Intellectual History.

Recibido: 16 de enero de 2020. Aceptado: 11 de marzo de 2020. 


\section{Introducción}

El siglo XVIII es la época en que las producciones culturales medievales (escritos, obras de arte, edificios, música) empezaron a suscitar el interés de los intelectuales, en tanto que conjunto circunscrito cronológica e ideológicamente. Dentro de este conjunto, las obras literarias alimentaron el imaginario y la ciencia de los intelectuales ilustrados, contribuyendo a su afán reformador. Sin embargo, las modalidades de recepción de la literatura medieval en el siglo XVIII han sido poco estudiadas. En una reciente publicación, algunos autores han intentado resaltar las principales características de dicha recepción, interesándose por los diferentes estudios sobre la literatura medieval, por las principales redes intelectuales y por los actores que participaron de este movimiento de rescate en el Siglo de las Luces ${ }^{1}$. También existen estudios específicos dedicados a algunas figuras emblemáticas de la recepción de los textos medievales ${ }^{2}$.

Entre los diversos estudios dieciochescos sobre el medioevo se encuentran aquellos que conciernen a la labor de Alfonso X. La recurrencia de esta figura modélica tenía que ver con los intereses particulares de los intelectuales de la época. Donald C. Buck publicó en 1986 un trabajo sobre la recepción de la obra alfonsí en el siglo XVIII ${ }^{3}$. El autor estima que los ilustrados se interesaron por la vida y la obra del Rey Sabio por tres motivos. Primero, porque sus escritos tenían un valor histórico y filológico sin par. Mediante la lectura de los textos alfonsíes, los hombres del siglo XVIII tenían la impresión de acercarse a los orígenes mismos de la lengua española de la que el rey aparecía como el primer exponente. Este aspecto lo investigó Gregorio Mayáns y Siscar tanto en sus Orígenes de la lengua española (1737) como en su Retórica (1757).

1 Véase Jesús Cañas Murillo y José Roso Díaz (eds.), En los inicios ilustrados de la Historiografía Literaria Española: Miradas sobre la Edad Media y el Siglo de Oro (1700-1833), San Millán de la Cogolla, Cilengua, 2019.

2 Véase en particular Miguel Ángel LAdERo QueSADA, «Campomanes medievalista», in Gonzalo AnEs y Álvarez de Castrillón, Campomanes en su II Centenario, Madrid, Real Academia de la Historia, 2003, págs. 35-116.

3 Donald C. Buck, «Alfonso X as Role Model for the Eighteenth-Century Ilustrados», Romance Quarterly, 33:3 (1986), págs. 263-268. 
Segundo, porque los ilustrados percibían al monarca como un pionero en el terreno científico. Quedaron fascinados por la capacidad de integración que demuestra su obra, en particular en lo relativo a las traducciones. Las aportaciones lingüísticas y científicas de las tres culturas suscitaban la admiración de estos intelectuales que aspiraban a alimentar el pensamiento español con las innovaciones filosóficas extranjeras. Por último, consideraban a Alfonso X como un paradigma de los ideales intelectuales que ellos mismos pretendían encarnar. Alfonso X había sacado provecho de los saberes de su tiempo para proponer una obra monumental, una verdadera gloria de las letras española. Si bien los principales aspectos del estudio de la obra alfonsí en el siglo XVIII han sido estudiados como hemos indicado, aún queda mucho por hacer en detalle. Un primer aspecto que investigar son las fuentes gracias a las cuales los intelectuales del siglo XVIII pudieron conocer a Alfonso X y su labor. Luego, nos interesaremos por las aportaciones de los autores dieciochescos al conocimiento del Rey Sabio. Por último, a partir del ejemplo de la recepción de una obra alfonsí, veremos cómo el campo de estudios alfonsíes empezó a constituirse, suscitando el interés de los ilustrados.

\section{El Alfonso X dieciochesco, figura de la continuidad historiográfica}

Es común la idea de que el siglo XVIII fue la época del redescubrimiento de Alfonso X. Después de cinco siglos de olvido, la obra y la figura eminente de aquel que fue apodado el Rey Sabio, habrían sido recuperadas gracias a los estudios archivísticos impulsados por los ilustrados. Los intelectuales del siglo XVIII tenían la convicción de que habían rescatado la obra del soberano, una obra olvidada desde mucho tiempo:

¡Ah! Las densas nieblas que le cercaron en sus postrimeros años, han tardado quinientos años en disiparse [...] Pero pasarán, mejor diré, pasaron tan fatales influjos: llegó el reinado de la razón, la época de la crítica, el dominio de la justicia, el tiempo del discernimiento, el imperio de las ciencias, el siglo de las luces, y a los venideros se transmitirá ilesa la memoria de Don Alfonso el Sabio ${ }^{4}$.

Además de la isotopía de la luz, muy propia de la época, el autor de esta aseveración explota la metáfora de la niebla. Insiste asimismo en la incertipág. 61 .

4 D. Joseph de Vargas y Ponce, Elogio del Rey don Alonso el Sabio, Madrid, Joachín Ibarra, 1782, 
dumbre que rodea a los acontecimientos de finales del reinado de Alfonso X, incertidumbre que pretende haber contribuido a disipar. En realidad, todavía no se han aclarado del todo estos acontecimientos ni las condiciones de vida y de producción del monarca «en sus postrimeros años», es decir, durante su exilio sevillano. Este fragmento también introduce una visión providencial de la recuperación de la memoria alfonsí. Proponiendo una forma de analogía entre los componentes de la labor intelectual del Rey Sabio y las características del Siglo de las Luces, subraya la idea de que el siglo XVIII parecía ser el momento adecuado para el redescubrimiento y la exaltación de su labor. Los ilustrados se convertían así en transmisores de la obra desestimada de un soberano excepcional, obra que habían integrado plenamente a la historia intelectual de la nación española.

Sin embargo, se trata de una afirmación hiperbólica y en parte errónea, de la que los ilustrados, al utilizarla, eran plenamente conscientes. En efecto, no hay ruptura concreta en la perpetuación de la memoria de Alfonso X o de su obra entre finales del siglo XIII y comienzos del XVIII. Sin embargo, es de notar que el conocimiento que se tenía de ellas era bastante parcial. Desde un punto de vista biográfico, Alfonso X aparecía en varias crónicas, a menudo de forma poco favorecedora, ya que lo acompañaba una leyenda negra. Además de un tumultuoso final de reinado, en que tuvo que enfrentarse con los principales estamentos del reino y con su hijo Sancho, también circulaba una historia según la cual Alfonso X habría pronunciado una blasfemia ${ }^{5}$. Perpetuada durante siglos, esta leyenda e imagen negativa del monarca incluyó progresivamente una serie de matices de corte estrictamente político o bien más personales ${ }^{6}$. Personaje histórico ambiguo, Alfonso $\mathrm{X}$ fue descrito como un pésimo gobernante versado en artes mágicas. Este juicio tuvo una expresión particularmente virulenta bajo la pluma del jesuita Juan de Mariana, quien, en su Historia de Rebus Hispaniae, redactaba una sentencia que iba a tener una fortuna perenne:

Don Alonso, rey de Castilla, era persona de alto ingenio, pero poco recatado, sus orejas soberbias, su lengua desenfrenada, mas á propósito para las letras que

\footnotetext{
5 Georges Martin, «Alphonse X maudit son fils», Atalaya, 5, 1994, págs. 151-179 y Leonardo Funes, «La blasfemia del Rey Sabio: itinerario narrativo de una leyenda (primera parte)», Incipit, 13 (1993), págs. 51-70; Leonardo FunEs, «La blasfemia del Rey Sabio: itinerario narrativo de una leyenda (segunda parte)», Incipit, 14 (1994), págs. 69-101; Leonardo FunEs, «La leyenda de la blasfemia del Rey Sabio: revisión de su itinerario narrativo", e-Spania, 25 (2016).

6 Sobre esta cuestión pueden consultarse Jean-Pierre JARDIN, «La figure du roi Alphonse X chez quelques chroniqueurs du Xve siècle», Cahiers de linguistique hispanique médiévale, 20 (1995), págs. 75-96 y Alejandro Rivera García, «La leyenda sobre la blasfemia de Alfonso X: un episodio de la conflictiva relación entre especulación teórica y razón de estado», eHumanista, 3 (2015), págs. 426-451.
} 
para el gobierno de los vasallos; contemplaba al cielo y miraba las estrellas; mas en el entretanto perdió la tierra y el reino ${ }^{7}$.

La paradoja de tal formulación, que consideraba a Alfonso X más como un buen astrólogo que como un buen gobernante, radica en el hecho de que los escritos astronómicos patrocinados por el soberano seguían siendo, en su mayor parte, desconocidos. El juicio de Mariana determinó en gran parte la recepción de lo alfonsí hasta bien entrado el siglo XVIII.

El primer historiador en buscar las razones de semejante descrédito fue Juan de Ferreras. Entre 1720 y 1721, el dominico publicó los dieciséis volúmenes de su Historia de España. En el sexto volumen incluyó una larga presentación de Alfonso X en la que sobresalen dos aspectos novedosos ${ }^{8}$. Primero, el uso de múltiples fuentes, tanto extranjeras como nacionales, identificables en el texto gracias a menciones de títulos o autores en bastardilla. La inclusión de materiales tan diversos ha de relacionarse con el cargo de bibliotecario mayor de la Biblioteca Real que ocupaba Juan de Ferreras, lo que favoreció sin duda la consulta de documentos históricos hasta entonces inexplotados. Segundo, cabe señalar que el autor propuso un balance historiográfico inédito. Enumerando los principales hechos que marcaron el reinado de Alfonso X, Juan de Ferreras insistió en que, a pesar de los eventos que enturbiaron el final de su reinado, fue el relato partidista de la Crónica de Alfonso $X$ el elemento central de una visión errónea de sus acciones:

[...] Principe desgraciado, no tanto por la variedad de successos de su Reynado, quanto porque la ignorancia, ò la malicia de el que compuso su Chronica, le dejò mal puesto con la posteridad, levantándole gravissimos testimonios, y disturbando la serie de sus verdaderas acciones; como se irà reconociendo, comprobando con monumentos seguros la falsedad de lo que se le ha imputado, y poniendo en Chronologia sus hechos, para que se deshagan las nieblas, que han oscurecido su fama, en tantos autores, como siguieron los errores de su Chronica9 $[. .$.

Una vez más, se trata de deshacer las nieblas. Aunque recuerde los fundamentos de la leyenda negra asociada al soberano, Juan de Ferreras ofrece un balance matizado del reinado de Alfonso X. Concluye su cronología recordando que

\footnotetext{
7 Francisco Pi i Margall (ed.). Juan de Mariana. Historia de España, 2 vols., Madrid, Rivadeneyra, 1854, vol. 1, XIII, XX, pág. 396.

8 Juan DE Ferreras, Historia de España, vol. 6, Madrid, Imprenta de Francisco de el Hierro, 1720, págs. 219-351.

9 DE Ferreras, Historia de España, págs. 221-222.
} 
el rey tuvo por principal mérito el haber promocionado las letras y los letrados en una época en que, según escribe, gran parte de la población carecía de cultura:

Fue igualmente valeroso, como lo testifica lo que hemos referido de sus acciones: magnifico, y ambicioso de gloria; y para mantenerla tan profuso, que le perdieron el amor, y la voluntad sus vassallos, de que resultò verse en el miserable estado en que muriò. Algunos dijeron, que en su sabiduría le havia desvanecido tanto, que se dejò decir: que si el huviera de hacer el mundo, le hiciera mejor, y que por esto le havia castigado Dios; pero esto à nuestro juicio es quento: $\mathrm{y}$ lo cierto es, que toda su vida fue aficionado à las letras, y gran favorecedor de los que las professaban, deseando de esta suerte cultivar la rudeza Española de aquellos Siglos ${ }^{10}[\ldots]$

La Historia de Ferreras tuvo una gran difusión por Europa gracias a traducciones $^{11}$. Su contribución al conocimiento de la figura de Alfonso X en las demás naciones europeas queda por investigar.

Desde un punto de vista bibliográfico, el paso a la posteridad de Alfonso X se debía principalmente a dos obras. Por un lado, las Siete Partidas, que se editaron y reimprimieron nueve veces entre 1491 y 1789 y que habían perpetuado su fama en los reinos hispánicos. Este texto jurídico, difundido tanto en la Península Ibérica como en los reinos hispano-americanos, constituía la suma de derecho por antonomasia. Agrupando y ordenando una multitud de principios legales heredados tanto del derecho romano como del derecho canónico, las Partidas se consideraron un texto idóneo para adaptarse a diversos contextos. Su valor intrínseco radicaba precisamente en esta versatilidad ${ }^{12}$. Un proyecto de reedición nació en 1796 y se concretó en 1807 bajo la forma de una publicación en tres volúmenes patrocinada por la Real Academia de la Historia. En el campo de los textos jurídicos alfonsíes, también ha de mencionarse el interés por el Fuero Real (c. 1255). Este texto de derecho municipal fue impreso en 1781 siguiendo las pautas editoriales de la versión glosada por Montalvo de $1569^{13}$, pero su consulta no excedió el mero interés filológico. El uso de ambas sumas coincide con la ambición que tenían los ilustrados de dotar al reino de un corpus legal a partir de textos pertenecientes al patrimonio nacional.

10 DE Ferreras, Historia de España, pág. 350.

11 La obra de Ferreras fue traducida al francés y publicada entre 1742 y 1551, y al alemán entre 1754 y 1772 .

12 Véase al respecto Jesús Rodríguez-Velasco, «La urgente presencia de las Siete Partidas», La corónica, 38:2 (2010), págs. 99-135.

13 Véase el estudio de Jesús Vallejo Fernández de la Reguera, «El Fuero Real bajo las luces o las sombras de la edición de 1781», Initium: Revista catalana d'historia del dret, 1 (1996), págs. 611-644. 
A escala europea, fueron sin duda las Tablas astronómicas, también denominadas Tablas alfonsinas, las que contribuyeron al renombre de Alfonso X. Estos datos y cálculos astronómicos, acompañados por sus cánones, es decir por las instrucciones en prosa que permiten entenderlos, han sido considerados como el principal legado del Rey Sabio a la ciencia europea ${ }^{14}$. Sin embargo, Jean-Patrice Boudet, que estudió la difusión de este trabajo, ha cuestionado algunas certidumbres ${ }^{15}$. Abandonadas en el siglo XVI a favor de las tablas prusianas, las Tablas atribuidas al Rey Sabio, aunque probablemente compiladas por Juan de Sajonia en los años 1320 en París, gozaron de una fama innegable en la historia de la astronomía. Desde un punto de vista muy general, la fortuna de la obra alfonsí se debió principalmente a estas dos obras frecuentemente citadas y utilizadas. En vísperas del siglo XVIII, el conocimiento de la empresa intelectual del Rey Sabio en España no se limitaba a ellas, puesto que durante el siglo XVII se publicaron tres síntesis generales integradas por varios títulos.

La primera de ellas fue la Bibliotheca Hispana vetus (1696, Roma) del diplomático Nicolás Antonio, que aprovechó su estancia en Roma para redactar dicha obra, en la que catalogó varios textos de Alfonso X. Al final del quinto capítulo del octavo libro de su Bibliotheca enumera: las Cantigas de Santa María, tituladas De los loores y milagros de nuestra Señora, sin duda por cierta confusión con la obra de Gonzalo de Berceo; las Tabularum Astronomicum en las que incluyó un excurso sobre el entorno científico del rey, deteniéndose en varios astrónomos que colaboraron con él o fueron coetáneos suyos; la traducción al castellano del Tetrabiblos de Tolomeo; el Libro de Alexandre; los Cánones Albateni; la Historia general de España, que corresponde a la Estoria de España; La grande e general estoria que es el título bajo el cual se conocía en ese momento la General Estoria, obra de la que cita el prólogo y las primeras líneas

14 Véanse Emmanuel Poulle y Denis SAvoIe, «La survie de l'astronomie alphonsine», Journal for the History of Astronomy, 29 (1998), págs. 201-207; José Chaвás \& Bernard R. Goldstein (eds). The Alfonsine Tables of Toledo, Dordrecht-Boston-London, Kluwer Academic Publishers, 2003.

15 Boudet propone una reevaluación completa de la cuestión. A diferencia de Poulle, que atribuye la obra a varios colaboradores judíos del rey, sugiere que el éxito de las Tablas no se puede atribuir al mismo Alfonso X, sino a los astrólogos parisinos de los años 1320, entre ellos a Juan de Sajonia, redactor de los Cánones de mayor difusión. También señala el hecho de que la edición de Chabás y Goldstein fue realizada a partir de un único manuscrito del siglo Xvi, lo cual no constituye en sí una prueba de la difusión de las Tablas. Recuerda que Chabás y Goldstein ya habían descartado el dudoso almanaque portugués editado por Rico y Sinobas en 1866 como uno de los avatares de la obra. Por último, estima que la refundición tardía de los Cánones Albateni, probablemente entre 1280 y 1284, demuestra que los colaboradores del rey no consideraban las denominadas Tablas alfonsinas como un instrumento de referencia. De todo ello deduce que dichas Tablas ya eran un mito en el momento de su recepción parisina. Véase Jean-Patrice BoudET. Entre science et nigromance. Astrologie, divination et magie dans l'Occident médiéval (XII $-X V^{e}$ siècle), Paris, Publications de la Sorbonne, 2006, en particular págs. 46-47 y 283-285. 
del capítulo primero; La gran conquista de Ultramar y, por último, las Siete Partidas, de las que subraya el valor absoluto en tanto que suma de derecho ${ }^{16}$. La Bibliotheca fue reeditada en 1788 por Francisco Pérez Bayer. Dentro de este trabajo fundamental, por no decir fundacional, para la bibliografía moderna española, Alfonso X ocupaba, pues, un lugar destacado.

La segunda síntesis, de índole jurídica, suele atribuirse a Juan Lucas Cortés. En su De originibus Hispani iuris, compilación de fecha incierta, considerada la primera historia completa del derecho español, se interesa principalmente por las Partidas. La existencia de una publicación de Gerardo Ernesto de Frankenau (1703, Hannover) titulada Sacra Themidis Hispanae Arcana, con la que a menudo se confunde, sigue suscitando dudas acerca de la autoría de dicho estudio; la cuestión permanece a falta de ejemplares de la obra de Lucas Cortés ${ }^{17}$. Suele consultarse la editio secunda de la Sacra Themidis, preparada por Francisco Cerdá y Rico e impresa por Antonio Sancho en Madrid en $1780^{18}$.

Por fin, las Memorias historicas del rei D. Alonso el Sabio y observaciones a su chronica del Marqués de Mondéjar constituían, sin duda alguna, el estudio más completo sobre las producciones literarias de Alfonso $\mathrm{X}^{19}$. Es de notar que este estudio es el verdadero puente crítico entre el siglo XVII y el XVIII, porque, aunque se compuso a finales del siglo XVII, no fue editado hasta 1777 por Francisco Cerdá y Rico. En el libro VII de dichas Memorias, Mondéjar enumera la totalidad

16 «Las siete partidas del Rey D. Alonso nuncupatum hoc est, Hispane totius, tam sacre quam profane, tam publice quam privatce, quam civilis quam criminalis, ut vocant, jurisprudentice corpus absolutissimus [...]", Nicolás Antonio, Bibliotheca Hispana Vetus, Roma, 1696, VIII, V, XIV, 221, pág. 59.

17 Para algunos autores, de Frankenau se apropió el trabajo de Cortés: «D. Juan Lucas Cortés apparait dans la Bibliotheca Nova sous la plume de son grand ami D. Nicolás Antonio, qui le cite comme l'auteur d'une Vida y acciones del Santo Rey Fernando III de Castilla y León et d'un Memorial de la Casa de S. Diego de Ayala Herrera y Rojas Conde de la Gomera, et qui ne mentionne pas le principal titre de gloire de Cortés, son histoire du droit intitulée Sacra Themidis, parce que cette œuvre dût être écrite après 1684. Elle parut en 1703 sous le nom de Gérard Ernest de Frankenau, secrétaire du roi de Danemark, qui s’était vraisemblablement approprié le texte de Cortés par l'intermédiaire de Frédéric de Ehrencron, envoyé de Frédéric IV de Danemark auprès de Philippe V, comme le laisse entendre D. Gregorio Mayans dans la lettre accompagnant la préface de l'édition faite par Cerda en 1780, qui restitua l'œuvre à son véritable auteur.», Janine FAYARD, Les membres du Conseil de Castille à l'époque moderne (1621-1746), Genève, Droz, 1979, pág. 501. Sin embargo, hay quien sigue manteniendo que esta cuestión no se ha resuelto del todo en la medida en que desconocemos en realidad el texto de Juan Lucas Cortés, supuestamente titulado De originibus Hispani iuris. De hecho, se trataría de dos textos independientes. Véase por ejemplo Miguel Ángel GonZález dE SAN SEgundo, «Juan Lucas Cortés (1624-1701): notas sobre su origen familiar y actividad profesional», Anuario de Historia del Derecho Español, 71, 2001, págs. 575-584.

18 Francisco Cerdá y Rico (ed.), Sacra themidis hispanae arcana, jurium legumque ortus, progressus, varietates et observantias, cum praecipuis glossarum commentariorumque, quibus illustrantur, auctoribus, et fori hispani praxi hodierna, publicae luci exponit D. Gerardus Ernestus de Franckenau, Editio secunda, Madrid, Antonio Sancho, 1780.

19 Francisco Cerdá y Rico (ed.), Gaspar Ibáñez de Segovia Peralta y Mendoza, Memorias historicas del rei D. Alonso el Sabio y observaciones a su chronica, Madrid, Joachín Ibarra, 1777. Los capítulos dedicados a la obra de Alfonso X ocupan el libro séptimo, págs. 437-473. 
de las obras de Alfonso X entonces identificadas. Para los textos jurídicos, cita el Fuero Real, las Siete Partidas y los privilegios otorgados por el rey. Mondéjar evoca en el capítulo siguiente el uso de la lengua castellana en diversas traducciones promovidas por el soberano. Cuestiona a continuación la atribución al rey de un libro titulado Philosophia oculta o Clavis Sapientiae ${ }^{20}$. Dicho texto se encuentra en el quinto volumen del compendio de tratados filosófico-esotéricos que editó Lázaro Zetzner en Estrasburgo bajo el título de Theatrum Chemicum ${ }^{21}$. Sabemos hoy que existe una Clavis Sapientiae que forma parte de la colección septenaria de textos mágicos que conforman el Liber Razielis, colección hebrea traducida al latín en la corte alfonsí2 ${ }^{2}$. No obstante, no hay coincidencia ninguna entre ambos textos ${ }^{23}$, lo cual confirma las reservas de Mondéjar en cuanto a la atribución de este escrito a Alfonso $\mathrm{X}^{24}$. En el dominio astronómico, se refiere a las Tablas. Se equivoca al evocar tres textos que caracteriza como «poéticos»: las Cantigas de Santa María, una Vida i hechos de Alexandro el Grande de la que precisa que se redactó en sextillas y el Libro de las Querellas. Sabemos ahora que el Libro de Alexandre es obra de un autor anónimo de principios del siglo XIII. Al atribuírselo a Alfonso X, Mondéjar reproduce una información que circulaba en su época ${ }^{25}$. En cuanto al Libro de las Querellas, el académico Emilio Cotarelo y Mori estudió ya hace tiempo el problema de la inexistencia de dicho texto $^{26}$. Mondéjar atribuye también al Rey Sabio la paternidad del Thesoro, obra del genovés Brunetto Latini. Por fin, presenta las magnas obras históricas que son la General Estoria y la Estoria de Espana. En definitiva, en las Memorias se mencionan ocho de las cuarenta y seis obras de Alfonso X, traducciones incluidas, conocidas hoy en día.

20 Cerdá y Rico (ed.), Memorias historicas, págs. 454-455.

21 Lázaro ZETZNER, Theatrum Chemicum, praecipuos selectorum auctorum tractatus de chemice et lapidis philosophici antiquitate, veritate, jure prcestantia, \& operationibus, vol. 5, Argentorati, Sumptibus Hæredum Lazari Zetzneri, 1622, págs. 855-879.

22 Ms. Reg. Lat. 1300, fols. 10r.-21v. de la Biblioteca Vaticana.

23 El texto del Clavis contenido en el Theatrum Chemicum es un breve tratado de filosofía aristotélica sobre la generación y la corrupción de las materias que fue compuesto, con toda probabilidad, durante el Renacimiento y atribuido a Alfonso X (Alfonso V) en la edición de Zetzner. No se corresponde en nada con el contenido de la Clavis del Liber Razielis que trata de la doctrina de Salomón y de los planetas.

${ }_{24}$ El tema ha sido profundizado recientemente por Kirsten KenNEDY, Alfonso X of Castile-León, Royal Patronage, Self-Promotion and Manuscripts in Thirteenth-century Spain, Amsterdam, Amsterdam University Press, 2019, págs. 60-62.

25 Sobre la cuestión de esta atribución, véase Jesús Cañas Murillo, «En los orígenes de la historiografía literaria española: el mester de clerecía en la era de la Ilustración» in Jesús CaÑas MuriLlo y José Roso DíAz (eds.), En los inicios ilustrados, págs. 27-66, en particular págs. 36-37.

26 Emilio Cotarelo y Mori, «El supuesto libro de Las Querellas del rey D. Alfonso el Sabio», in Emilio Cotarelo y Mori, Estudios de historia literaria de España, Madrid, Imprenta de la Revista Española, 1901, t. 1, págs. 5-31. 
El conocimiento que los hombres del siglo XVIII tenían de Alfonso X era, pues, incompleto y bastante tributario de mitos y presupuestos heredados de la historiografía clásica. En los albores del siglo XVIII se conocía esencialmente a Alfonso $\mathrm{X}$ a través de unos pocos textos históricos, jurídicos y astronómicos. En España, las Siete Partidas lo habían eclipsado todo, o casi. Los intelectuales del siglo XVIII estaban familiarizados con los textos alfonsíes y en particular con la gran suma legal de Alfonso X. En un primer momento, intentaron prolongar, completándola, la aproximación sinóptica propuesta por algunos autores del siglo XVII, pero la iniciativa que realmente dio una nueva dimensión al corpus alfonsí fue el trabajo realizado por la Comisión de Archivos ${ }^{27}$.

\section{Mediados del siglo XVIII: renovación historiográfica y posturas críticas}

El objetivo principal de dicha comisión era revisar los fondos catedralicios del reino para exhumar todos los escritos jurídicos y diplomáticos susceptibles de legitimar el Real Patronato. En septiembre de 1749, por orden real, Andrés Marcos Burriel y Francisco Pérez Bayer fueron nombrados para dirigir esta comisión. También formaron parte de ella Pedro Burriel, hermano del jesuita, encargado de la parte administrativa; Andrés y Carlos de Simón Pontero, quienes investigaron respectivamente las documentaciones del Reino de Aragón y de la provincia de Madrid; Francisco Javier de Santiago y Palomares, un famoso calígrafo toledano, don Ascensio Morales, así como varios canónigos reclutados en las parroquias visitadas. La compilación de este conjunto documental debía permitir establecer un nuevo concordato con la Santa Sede, tras el fracaso de las negociaciones de $1737^{28}$. Sin embargo, se sumaron progresivamente a este propósito inicial nuevos objetivos, vinculados con intereses intelectuales personales, en particular hacia los textos jurídicos y litúrgicos ${ }^{29}$. Algunos integrantes de la Comisión empezaron así a estudiar los fondos revisados y a difundir las noticias de sus hallazgos a través de informes, correspondencias o estudios, suscitando el interés de las redes intelectuales y sociales de las que formaban parte.

27 Para un estudio completo véase José Simón DíAz, «El reconocimiento de los Archivos Españoles en 1750-1756», Revista bibliográfica y documental, 4:1-4 (1950), págs. 131-171.

28 Para un estudio completo de la cuestión véanse Antonio Mestre, «La Iglesia y el Estado. Los Concordatos de 1737 y 1753», in Francisco CÁnovas Sánchez et alii (dirs.), La época de los primeros Borbones. Vol. 1: La nueva monarquía y su posición en Europa (1700-1759), Madrid, Espasa Calpe, 19964, págs. 277-333 y Juan Francisco BaLTAR Rodríguez, «Iglesia y Estado: los Concordatos de 1737 y 1753», in José Antonio EscuDERo LóPEZ (dir.), La Iglesia en la historia de España, Madrid, Marcial Pons, 2014, págs. 661-673.

29 Véase la síntesis propuesta en los primeros capítulos de Susan Boynton, Silent Music. Medieval Song and Construction of History in Eighteenth-Century Spain, Oxford, Oxford University Press, 2011. 
El centro neurálgico de la tarea emprendida por la Comisión fue el archivo capitular de Toledo. Allí, la empresa parecía desmesurada; la documentación vertiginosa. Los archivos contenían documentos pertenecientes a la sede episcopal, así como parte de los fondos hereditarios de la monarquía, fondos cuya extensión y contenidos escapaban a los propios miembros del cabildo. En total y sólo para la ciudad de Toledo, Burriel y su equipo transcribieron cerca de dos mil documentos. Entre estos manuscritos figuraban varias obras de Alfonso X desconocidas hasta entonces: el Setenario, el Libro de la Ochaua Espera, los tratados de construcción y utilización de instrumentos astronómicos que conocemos bajo el título de Libros del saber de astronomía, el Libro de axedrez, dados e tablas, y también un conjunto de manuscritos jurídicos e históricos que permitió perfeccionar los estudios filológicos sobre los textos que ya eran conocidos.

Con estas investigaciones, el corpus alfonsí adquirió nuevas dimensiones. Fue a medio camino entre interés intelectual, promoción de la nación y del pueblo español, como el redescubrimiento, por no decir la invención de la obra de Alfonso X, se inició. Burriel fue el primero en transcribir, anotar y comentar estos escritos. Sin embargo, su trabajo personal tuvo, en un primer momento, escasa difusión. La coincidencia de la Comisión con el proyecto de la España sagrada de Enrique Flórez (1756-1771), la expulsión de los jesuitas en 1767, así como la confiscación de su biblioteca personal por orden de Richard Wall, tuvieron como consecuencia el desconocimiento de su labor. Otros autores sacaron provecho de su trabajo, integrándolo en sus producciones personales. Terreros y Pando escribió con él la Paleografía española $(1755)^{30}$, eclipsando en gran parte su coautoría. Fray Martín Sarmiento redactó sus Memorias para la historia de la poesía y poetas españoles (1775) con énfasis en los poemas mariales de Alfonso $\mathrm{X}^{31}$. Este trabajo constituía una cumbre en las investigaciones dieciochescas sobre la poesía española medieval ${ }^{32}$. En su correspondencia, Fray Martín Sarmiento también recordaba que las Cantigas fueron escritas en gallego, lo cual se oponía a la idea de la anterioridad del castellano en tanto que lengua vernácula de uso más antiguo ${ }^{33}$. Por fin, Joseph Rodríguez de Castro

\footnotetext{
30 P. Estevan Terreros y Pando, Paleografía española, Madrid, Joachín Ibarra, 1758.

31 Fr. Martín SARmiento, Memorias para la historia de la poesía y poetas españoles, Madrid, Joachín Ibarra, I775.

32 Para un listado completo de los trabajos sobre la poesía alfonsí producidos durante el siglo XVIII, véase Joseph Thomas Snow, The Poetry of Alfonso X: An Annotated Critical Bibliography (1278-2010), Woodbridge, Tamesis, 2012, en particular págs. 3-6.

33 «Lo innegable es que las coplas gallegas que andan escritas no ceden en antigüedad a las castellanas. Hablo de las que el rey D. Alfonso el Sabio escribió en gallego en loor de nuestra Señora.» in Manuel Murguía (ed.), Fray Martín Sarmiento, Carta a Terreros sobre la lengua gallega, Buenos Aires, Editorial Nova, 1943, pág. 66.
} 
compiló la Biblioteca española, cuyo tomo segundo (1786) propone un repertorio de las obras alfonsíes ${ }^{34}$. La Biblioteca se apoya en estudios anteriores, y sugiere que Rodríguez de Castro estaba al tanto de las investigaciones más recientes. El autor organizó su propia historia de los textos alfonsíes, restableció la autoría del Libro de Alexandre y añadió a la lista de textos conocidos el Libro de las Tafurerías y el Libro de la Montería. La mayor aportación de la Biblioteca fue de índole filológica. Para Alfonso X, Rodríguez de Castro se basó en el fondo escurialense. Este enfoque le permitió completar el trabajo de la Comisión e identificar numerosos códices inexplotados. Incluyó en su estudio largas citas sacadas de estos nuevos testimonios. De hecho, delimitó un conjunto de textos y manuscritos que presentaban variantes valiosas a la hora de proceder a un examen filológico de los escritos atribuidos a Alfonso X.

Al margen de la herencia de Burriel, estudios filológicos más puntuales salieron a la luz. Las Reflexiones sobre un punto de el mérito literario de el Rey D. Alonso de Isidoro Bosarte constituye un buen ejemplo del interés variopinto que suscitó la producción escrituraria patrocinada por el Rey Sabio. El tema central de las Reflexiones es el uso por parte de la cancillería alfonsí del «pergamino de paños», un tipo de soporte de escritura cuyo origen y materialidad se investigan a partir de un comentario de la ley V del título XVIII de la Tercera Partida, de varios documentos del siglo XIII y de algunos datos históricos o biográficos sobre Alfonso $\mathrm{X}^{35}$. Tal como indica el título del breve ensayo, se trata esencialmente de una pesquisa codicológica destinada a resaltar una innovación propia del soberano. La primera hoja indica que el estudio de Bosarte fue examinado y criticado por Juan Bautista Muñoz y Ferrandis y Juan Antonio Pellicer. Sus notas preceden al estudio en el manuscrito que se conserva en la Biblioteca de la Real Academia de la Historia.

Amén de este ensayo técnico, las Partidas siguieron comentándose en la mayor parte de los textos de jurisdicción o de reflexión política del siglo XVIII. Dos fueron los principales promotores de la suma legal en la Península ibérica. El primer de ellos, José Berní y Catalá, fue jurista, abogado de los Reales Consejos e impulsor de la fundación del Colegio de Abogados de Valencia. Su trayectoria personal, así como sus obras, han sido estudiadas en varios trabajos de referencia ${ }^{36}$. Siguiendo las directrices de la política carlista, el jurista se esforzó

34 Joseph Rodríguez de Castro, Biblioteca española. Tomo Segundo que contiene la noticia de los escritores gentiles españoles, y la de los christianos hasta fines del siglo XIII de la Iglesia, Madrid, Imprenta Real, 1786, t. II, págs. 625-689.

35 El texto se conserva en el ms. 11-08234 de la Biblioteca de la Real Academia de la Historia.

36 Véanse los estudios biobibliográficos de Vicente Castañeda Alcover, «El Dr. D. José Bemí y Catalá, jurisconsulto valenciano», Revista de ciencias jurídicas y sociales, 1 (1918), págs. 187-235, 353-437 y 548- 
en reintroducir el derecho real en las aulas, ya que en las universidades únicamente se estudiaba el derecho común. Se involucró en varios debates acerca de la vigencia y del valor del derecho real. Demostrando la preeminencia de dicho derecho, Berní y Catalá se opuso a la consideración de las Partidas como derecho supletorio ${ }^{37}$. En 1758 publicó un Índice de las Leyes de las Siete Partidas con el fin de facilitar el acceso a varias definiciones útiles para los juristas. Al año siguiente, publicó los Apuntamientos sobre las Leyes de Partida, en los que, al margen del texto de López de 1555, propuso una serie de notas y reflexiones sobre el derecho alfonsí, así como una concordancia con el cuerpo legal que estaba vigente entonces, es decir la Nueva Recopilación ${ }^{38}$. El autor, consciente de la antigüedad del texto que ofrecía al lector, precisó en su prólogo la naturaleza de su trabajo de actualización:

Como estas Leyes de las Partidas tienen tanta antigüedad, y los tiempos y experiencias han variado mucho, es consiguiente que se hallen corregidas y derogadas algunas proposiciones; y por esto devemos poner particular cuidado en distinguir los tiempos y saber las limitaciones modernas, correcciones o derogaciones ${ }^{39}$.

Añadió a esta justificación inicial una serie de datos sobre las Partidas y la producción jurídica del Rey Sabio. Así, propuso una breve historia de las ediciones y promulgaciones sucesivas de las Partidas, explicitó su afán vulgarizador y aludió a la figura de Jacobo de las Leyes, famoso jurista de la corte alfonsí. Los Apuntamientos obtuvieron la licencia de publicación real. Alcanzaron gran éxito y suscitaron la admiración de sus lectores más eminentes, como sugieren las cartas de aprobación y censura que los preceden, y ofrecen una buena idea de las instituciones que estaban al tanto de este trabajo ${ }^{40}$. Por fin, el jurista

596, y 2 (1919), 101-144; y Pedro NÁcher Hernández, El Doctor José Bemí Catalá, su vida y su obra, Valencia, Colegio de Abogados de Valencia, 1961.

37 Para todas estas cuestiones, véase Carlos Tormo Camallonga, «Berní y Catalá, el derecho común y las universidades», Cuadernos del Instituto Antonio de Nebrija, 3 (2000), págs. 279-316.

38 La Nueva Recopilación, promulgada el 14 de marzo de 1567 por Felipe II, tenía como objetivo la reunión de todas las disposiciones legales anteriores en un único volumen, sintetizando el Ordenamiento de Alcalá de 1348, el Ordenamiento de Montalvo de 1484 y las Leyes de Toro de 1505.

39 José Berní y Catalá, Apuntamientos sobre las leyes de Partida al tenor de las leyes recopiladas, autos acordados, autores españoles y practica moderna, Valencia, Herederos de Gerónimo Conejos, 1759, prólogo (sin foliación).

40 Entre los nombres de aprobadores y censores aparecen D. Gregorio Mayáns y Siscar, Joseph Malonda (jesuita y Catedrático de Teología de la Universidad de Gandía), D. Gaspar Cebrian de Cebrian (miembro del Consejo Real, de la Real Audiencia de Valencia y del Tribunal Militar de la Orden de Nuestra Señora de Montesa), D. Francisco Locella (miembro del Consejo Real y de la Real Audiencia de Valencia) y D. Juan Luis de Novela (Colegial del Mayor de Sevilla, Académico Surnumerario de la Real Academia de la Historia de Madrid y Ministro del Crimen en la Real Audiencia de Valencia). 
valenciano compiló en 1767 la edición glosada de 1555 con sus propios Apuntamientos, con el fin de ofrecer un volumen completo que permitiera abordar la suma jurídica de Alfonso X. Al desarrollar instrumentos de consulta y concordancias con los textos legales de su época, José Berní y Catalá desempeñó un papel fundamental en la transmisión de las Partidas en distintas redes sociales e intelectuales del siglo XVIII.

Otro gran lector y comentarista de la obra del Rey Sabio fue, sin duda alguna, Gaspar Melchor de Jovellanos. Aunque fue buen conocedor de la vida y de la obra de Alfonso X, citó casi exclusivamente en sus escritos las Partidas y el Fuero Real. Solía usar más particularmente las Partidas como fuente de referencias y ejemplos para sus propios ensayos reformadores. También comentó con sus correspondientes varios aspectos de la producción jurídica del monarca. Gracias al contenido de su correspondencia, sabemos que fue lector de algunos glosadores y comentaristas de las Partidas, en particular de Mondéjar y de Montalvo. En una carta que dirigió a Juan Nepomuceno Fernández San Miguel, fechada el 19 de junio de 1797, Jovellanos nos dejó un panorama bastante completo de sus conocimientos sobre el tema, así como de las fuentes que manejaba ${ }^{41}$. Tratando de la legislación, expuso sus opiniones sobre el uso de las Partidas y de otros textos legales en tanto que derecho supletorio tras la promulgación del Ordenamiento de Alcalá (1348). Conocía muy bien el texto de las Partidas, de la que encontramos 139 menciones en la totalidad de su producción escrita. Sacó de la suma legal el epígrafe del elogio, dirigido a Carlos III, que pronunció el 8 de noviembre de 1788 delante de los socios de la Real Sociedad Económica de Madrid ${ }^{42}$. Desde un punto de vista histórico, Jovellanos presentó las costumbres de la corte alfonsí al evocar las cazas y los torneos en su Memoria sobre las diversiones públicas ${ }^{43}$. Por tanto, uno de los autores más

41 «No tengo a la mano ni a Mesa, ni a Mayans, ni a Castro, ni la Themis hispana, ni la carta a Amaya, ni las Instituciones castellanas, que es decir, ningún autor de los que ilustraron algún tanto la historia de nuestra legislación. Es, por tanto, muy poco lo que usted debe esperar de mí.», citado en «De Jovellanos a Juan Nepomuceno Fernández San Miguel», in José Miguel Caso González (ed.), Gaspar Melchor de Jovellanos, Obras completas, III, Correspondencia $2^{a}$, Oviedo, Ayuntamiento de Gijón, Instituto Feijoo de Estudios sobre el siglo XVIII, KRK Ediciones, 1986, págs. 313-321.

${ }_{42}$ «É aun deben (los Reyes) honrar, é amar á los Maestros de los grandes saberes... por cuyo consejo se mantienen, é se enderezan muchas vegadas los Reynos. Rey don Alfonso el sabio en la ley $3 .^{a}$, título $10 .^{\circ}$ de la Partida 2. " », «Elogio de Carlos III. Leído a la Real Sociedad de Madrid por el socio don Gaspar Melchor de Jovellanos, en la Junta plena del sábado 8 de noviembre de 1788, con asistencia de las señoras asociadas» in Vicent Llombart i Rosa y Joaquín Ocampo SuÁrez-Valdés (eds.), Gaspar Melchor de Jovellanos, Obras completas, X, Escritos económicos, Oviedo, Ayuntamiento de Gijón, Instituto Feijoo de Estudios sobre el siglo XVIII, KRK Ediciones, 2008, págs. 669-685, pág. 669.

43 «Memoria sobre las diversiones públicas», in Elena de Lorenzo Álvarez (ed.), Gaspar Melchor de Jovellanos, Obras completas, XII, Escritos sobre la literatura, Oviedo, Ayuntamiento de Gijón, Instituto Feijoo de Estudios sobre el siglo XVIII, KRK Ediciones, 2008, págs. 193-318. 
famosos del siglo XVIII era un profundo conocedor de la obra del Rey Sabio y artífice de su pervivencia intelectual.

A finales de la centuria, también se redactaron estudios que quedaron inéditos sobre la figura de Alfonso X. Así, dos elogios contribuyeron a la rehabilitación historiográfica del soberano esbozada por Juan de Ferreras. Primero, José Vargas y Ponce redactó en 1782 un Elogio del Rey Don Alonso el Sabio. La Real Academia Española premió y editó este Elogio del joven gaditano, considerado la síntesis más completa del siglo XVIII sobre Alfonso $\mathrm{X}^{44}$. En este texto Vargas y Ponce pretende proponer un enfoque biobibliográfico novedoso, distinguiendo el elogio del mero estudio histórico:

Seguir paso a paso la vida de un Príncipe, descender hasta sus empresas menos importantes, y dar una prolixa noticia de los negocios en el que intervino, ó tuvo parte, podrá ser objeto de su historia; pero no ciertamente de su elogio ${ }^{45}$.

Vargas y Ponce inaugura su obra alabando la presencia del Sabio, Alfonso X por antonomasia, en la historia nacional:

El sabio, siempre útil, siempre apreciable, es blasón, es honor de la sociedad a quien cupo en suerte, todos los reinos, las edades todas le invidian, le apetecen y sus tareas son las delicias del Universo ${ }^{46}$.

En el caso del Rey Sabio, rechaza redactar un estudio simplemente factual. Al contrario, quiere realzar la dimensión más personal de la empresa alfonsí, interesándose por los méritos propios del soberano, así como por sus aportaciones tanto a la cultura y al destino de la nación española como a la ciencia de los reinos europeos de su época ${ }^{47}$. Presenta las producciones literarias, científicas y jurídicas del rey, viendo en su obra, cuya concepción se parece a los métodos ilustrados, un elogio en sít ${ }^{48}$. Con tono solemne y abundancia de recursos enfá-

44 «...] the most complete eighteenth-century vision of Alfonso, one which incorporates the synthetic viewpoints of Mayáns, Cerdá, and Sarmiento, but one which expands their image of Alfonso, through Vargas' more analytic perspective, into larger more heroic scale.», Buck, «Alfonso X as Role Model», pág. 265.

45 Vargas y Ponce, Elogio del Rey, pág. 12.

46 Vargas y Ponce, Elogio del Rey, pág. 4.

47 «Europa, por quien te son conocidos los cielos, es por Alfonso.», VARGAS Y PONCE, Elogio del Rey, pág. 38 .

48 Mientras habla de la realización de la Estoria de España, indica que: «No era menester mas para empeñar á nuestro Rey en la grande obra de una historia nacional. Consultó archivos, juntó noticias, adquirió luces, y presentó al fin una, que ella misma es su mejor elogio.», VARGas y Ponce, Elogio del Rey, pág. 38. 
ticos, el autor demuestra, sin embargo, un buen conocimiento de la trayectoria histórica de Alfonso X, ya que aclara las vicisitudes del asunto imperial, detalla las relaciones del rey con los soberanos musulmanes y propone un relato circunstanciado de la revuelta de los nobles.

El segundo elogio es el fruto del trabajo de Don Hernán Quiñones, «sócio literato de la Real Sociedad Bascongada» ${ }^{49}$. Su Elogio de Alfonso X, rey de Castilla y Leon, llamado El Sabio, publicado en 1786 y dedicado al conde de Floridablanca se parece mucho, desde un punto de vista temático general, al de Vargas y Ponce. Quiñones también empieza por definir el género literario en que se inscribe su texto:

Ya aparece lo árduo é impracticable de nuestro asunto: del Elogio que vamos hacer de Alfonso X, Rey de Castilla y de Leon, llamado comúnmente el Sábio, si hemos de contenernos dentro de los límites de la verdad, como que lo contrario sería formar un Poema ó Romance, mas presto que un Elogio o Panegírico: conmutar el oficio de Orador por el de Poeta, á quien es lícito dexarse poseer y arrebatar del furor y entusiasmo, preferir lo deleytable y ameno á lo verdadero, desfigurar y pintar del modo que agrada los objetos ${ }^{50}$.

Tras situar su escrito en el panorama literario, Quiñones trata del contexto histórico y aborda la producción literaria, así como los principales hitos del reinado alfonsí. También inserta en su elogio algunas digresiones, como por ejemplo sobre los Alfonsos ilustres de la historia de España — de Alfonso I el Católico a Alfonso XI, monarcas que tienen en común el haber luchado contra la presencia musulmana en tierras castellanas ${ }^{51}$ _, o bien la Astronomía ${ }^{52}$. El retrato que propone del rey es el de un sabio expuesto a las adversidades y a la incomprensión de sus coetáneos. Retomando los tópicos de su época acerca de una Edad Media oscurantista, el autor convierte a Alfonso X un verdadero ilustrado:

[...] Alfonso X, el más ilustrado de todos los Reyes, y acaso de todos los hombres de su siglo: valiente, generoso, aplicado, magnánimo; que no respira mas que la gloria de la Patria, lleno de amor á las ciencias, á las letras, los artes y la justicia,

49 Véase la portada de D. Hernán Quĩones. Elogio de Alfonso X, rey de Castilla y Leon, llamado El Sabio, Madrid, Don Plácido Barco López, 1786.

50 Quĩ̃ones. Elogio de Alfonso X, pág. IV.

51 Quiñones. Elogio de Alfonso X, págs. XXVIII-XXXIII. Quiñones recuerda que la especificidad del décimo es que fue nombrado Emperador.

52 Quiñones. Elogio de Alfonso X, págs. LI-LIII. 
hábil en el arte de la guerra, humano, clemente; en una palabra, digno de reynar, y gobernar una Nacion amada del Todopoderoso ${ }^{53}$.

$¡ O$ ilustracion la de Alfonso X, en unos Siglos tan atrasados, de ignorancia y barbarie, capaz de avergonzar y confundir á los que vivimos en otros tan adelantados, de claridad é ilustracion ${ }^{54}$ !

Subraya también la perseverancia y la habilidad política de Alfonso X a pesar la oposición de detractores. El principal mérito que atribuye al rey es el haber iniciado la formación de la Nación, concepto político-territorial esencial para los ilustrados ${ }^{55}$.

El siglo XVIII fue el momento en que las informaciones pertenecientes a diversos campos del saber (poesía, tratados astronómicos, obras jurídicas o historiográficas), en parte dispersas u olvidadas a la muerte del Rey Sabio, fueron agrupadas de nuevo para crear, a través del examen y de los comentarios de los intelectuales de la época, una visión unitaria de la empresa intelectual alfonsí, un verdadero corpus. Rehabilitando la figura del rey, los ilustrados esbozaron las líneas directrices de un campo del saber que son hoy en día los estudios alfonsíes. El redescubrimiento de los escritos de Alfonso X, eclipsados desde siglos por el interés casi exclusivo en las Siete Partidas, así como por la transmisión de la leyenda de la blasfemia del rey, abrió nuevos horizontes intelectuales, al proponer a aquellos hombres en busca del saber un modelo de soberano ilustrado, de enciclopedista insaciable y de promotor de los intereses nacionales. A pesar del proceso de renovación, el contexto propio del siglo ilustrado, así como la remota preeminencia del corpus legal alfonsí, siguieron determinando en gran parte la lectura de estos intelectuales. La obra alfonsí no fue únicamente un objeto de fascinación, sino también un terreno propicio para el ejercicio de la erudición. Los textos que lo componían interesaban a los hombres del siglo XVIII porque correspondían con sus concepciones del saber (promoción de la lengua castellana, defensa de la Nación a través de la forja de conceptos jurídicos, propensión a integrar saberes de origen extranjero). Para estudiar los manuscritos y las producciones alfonsíes, los miembros de la Comisión de Archivos movilizaron sus propios conocimientos.

53 Quiñones. Elogio de Alfonso X, pág. XVIII.

54 QuiÑones. Elogio de Alfonso X, pág. LXX.

55 «[... al grande empeño de Alfonso de formar y regular la Nacion, que es lo que le constituye y caracteriza de Rey Grande, Sabio, honra y lustre de Príncipes, ornamento de España, fundador de esta Monarquía [...]», Quiñones. Elogio de Alfonso X, pág. LXVIII. 
El descubrimiento del Setenario constituye un buen ejemplo de cómo los eruditos del siglo XVIII abordaron los escritos de Alfonso X, y más generalmente, medievales. Andrés Marcos Burriel dio con el Setenario en 1752 en el Archivo Capitular de Toledo. Fue uno de los grandes hallazgos de Burriel en lo que atañe a Alfonso X. Este texto constituía para él un verdadero enigma. El Setenario (c. 1284) es un texto legal —está dividido en unidades llamadas «leyes»— de tono enciclopédico. Constituye una reescritura compleja de las obras jurídicas, históricas y científicas de Alfonso $\mathrm{X}^{56}$. Tras retomar, bajo una forma amplificada, el doble prólogo de las Siete Partidas, propone un retrato de Fernando III y una propedéutica general, y se articula en torno a dos ejes temáticos generales. El texto contiene primero una historia de las creencias antiguas (animismo, idolatría y astrología) en tanto que prefiguraciones del ritual cristiano. Segundo, a través de una serie de correspondencias y analogías, demuestra cómo las costumbres y devociones paganas llevaron a la elaboración del septenario sacramental. Esta presentación final, inspirada por el contenido de la Primera Partida y por algunos textos de derecho canónico, constituye una verdadera profesión de fe que establece las normas de la práctica religiosa. De hecho, su contenido, a la vez muy parecido y en parte distinto de las Siete Partidas, llevó a Burriel a considerar la obra como una introducción al magno código legal. Habrá que esperar más de un siglo para que se ponga en tela de juicio esta afirmación y que el Setenario pase a tomarse no como un paratexto sino más bien como la versión más compleja, aunque inacabada, de las Partidas.

Burriel realizó cuatro copias del Setenario en 1752. Dentro de este conjunto, es posible repartir los manuscritos en dos pares: los manuscritos II02983 de la Biblioteca del Palacio Real y 12991 de la Biblioteca Nacional de España, que contienen la totalidad del texto a partir del manuscrito más antiguo conservado en los fondos toledanos, y los fragmentos correspondientes a las diez primeras leyes del Setenario, que se encuentran en un manuscrito de la Biblioteca Jovellanos ${ }^{57}$ y en el manuscrito HC 380/89 de la Hispanic Society

56 Me permito citar mi tesis Johan Puigdengolas, Pour une approche de la pensée alphonsine: le cas du Setenario (Castille-Léon, XIIème siècle), Universidad Toulouse Jean Jaurès, tesis doctoral inédita.

57 El manuscrito 26-14 de la Biblioteca Jovellanos está perdido, debido a su destrucción durante un incendio en la época de la Guerra Civil. Conocemos su existencia gracias a una recensión de Somoza (Julio Somoza de Montsoriu, Catálogo de manuscritos e impresos notables del Instituto de Jovellanos en Gijón, seguido de un índice de otros documentos inéditos de su ilustre fundador, Oviedo, Vicente Brid, 1883, pág. 26) que describe de forma detallada su contenido, identificándolo como un fragmento de las Partidas. También lo cita Jerry Craddock en Jerry R. Craddock, The Legislative Works of Alfonso X, el Sabio, Londres, Wolfeboro, Grant \& Cutler, 1986, pág. 40. 
of America. El examen de estos ejemplares es revelador del trabajo de Burriel y su equipo sobre la obra de Alfonso X. Pero antes de examinar el trabajo filológico y artístico sobre estos ejemplares, ha de recordarse primero que estas copias se realizaron en un contexto muy particular, ya que en 1752 se celebró el quinto centenario de la muerte de Fernando III. El Rey Santo también era una figura modélica para los ilustrados. Su papel decisivo durante la Reconquista parecía a los intelectuales dieciochescos una defensa de la integridad territorial y espiritual de la nación española. Al menos ocho estudios dedicados a este rey fueron redactados en la segunda mitad del siglo XVIII ${ }^{58}$. Por otra parte, el 12 de abril de 1752 fue creada por real decreto la Academia de Bellas Artes de San Fernando ${ }^{59}$. Esta institución, inaugurada bajo el patronazgo del Rey Santo, desarrolló una política artística que, al fomentar la investigación de las obras medievales, apuntaba a reformar los cánones estéticos y promover la imagen de una España devota y comprometida en la lucha contra los herejes ${ }^{60}$. En este contexto, el Setenario se convirtió en una de las piezas claves de la conmemoración de Fernando III, como parece indicar el exquisito ejemplar de las Memorias (ms. HC 380/89) dirigido por Burriel a Fernando VI, su homónimo y descendiente. Conviene recordar al respecto que el Setenario contiene el retrato más completo y original de Fernando III que proporciona la literatura medieval. Esta pieza de alabanza, elaborada a partir del catálogo de virtudes reales idóneas desarrollado en la Segunda Partida ${ }^{61}$, se extiende de las leyes II a IX. La concepción de las copias de Burriel, retomando estos elementos claves del contenido del Setenario, prolongó así los primeros trabajos de glorificación emprendidos por Enrique Flórez, en particular mediante su examen de las inscripciones de la sepultura del Rey Santo publicado como prefacio a su España Sagrada ${ }^{62}$. De esta forma, este texto medieval, al igual que muchos

58 Para la lista de dichos textos, véase Martín Ríos Saloma, «La figura de Fernando III en la historiografía moderna y contemporánea», in Carlos de Ayala Martínez \& Martín Ríos Saloma (eds.), Fernando III, tiempo de cruzada, Cádiz, Ediciones Silex, 2012, págs. 491-518, págs. 509-510.

59 Para un estudio completo, véase Claude BÉDat, L'Académie des Beaux-Arts de Madrid (1744-1808), Toulouse, Association des publications de l'Université de Toulouse-Le Mirail, 1974.

60 $[\ldots]$ to the eyes of these academicians, medieval art could help to reform the country, both from the inside and outside. Not only could it furnish a model for a more rational society in its architectural and religious practices, but it could also improve the image of the country by providing proofs of the piety, courage, wisdom, and artistic skills of the Spanish nation.», Matilde Mateo, «Medievalism and Social Reform at the Academy of San Fernando in Spain (1759-1808)», Studies in Medievalism, IX (1997), págs. 123-147, pág. 147.

${ }_{61}$ Sobre este tema véase Georges MARTiN, «Datation du Septénaire: rappels et nouvelles considérations», Cahiers de Linguistique et de Civilisation Hispaniques Médiévales, 24 (2001), págs. 325-342.

${ }_{62}$ Enrique Flórez, Elogios del Santo Rey Don Fernando, puestos en el Sepulcro de Sevilla en hebreo, y arabigo: Hasta hoy no publicados. Con las inscripciones latina y castellana, Madrid, Antonio Martín, 1754. 
otros, se convertía en un elemento de defensa e ilustración de la sensibilidad nacionalista que caracterizaba aquella época.

Las copias del Setenario también nos proporcionan valiosas informaciones acerca del trabajo filológico y estético sobre los textos medievales llevado a cabo por los ilustrados. Los manuscritos BR II-02983 y BNE 12991 fueron respectivamente copiados para formar parte de la Biblioteca Real y de la biblioteca personal del jesuita Burriel. En estos ejemplares, el texto original del Setenario está rodeado por una serie de notas eruditas y adendas. El manuscrito 12991 lleva una mención manuscrita en su primer folio que precisa que «las notas son del Padre Burriel», testimonio del trabajo crítico sobre el texto. Con sus notas, Burriel puso de relieve las rupturas semánticas, delimitó los movimientos argumentativos, evidenció la estructura lógica del tratado y glosó los términos oscuros. De forma general, los elementos añadidos tienen que ver con las habilidades personales y la formación de los miembros de la Comisión de Archivos. Un ejemplo revelador de este proceso de lectura crítica se encuentra en la primera ley del texto. En este capítulo incompleto, el Setenario enumera siete series de siete nombres divinos cuya inicial corresponde a cada una de las letras del nombre Alfonso. Cada nombre divino derivado del nombre real aparece en el manuscrito toledano rodeados por unos circulitos rubricados. Muchos de estos nombres de Dios provienen del latín, del griego o del hebreo, pero todos están escritos con grafía castellana. En las copias de 1752 se añadieron a estos grupos de óvalos otras series similares con la grafía hebrea o griega original de los nombres divinos citados. Es muy probable que esta novedad haya sido introducida por Francisco Pérez Bayer, cuya formación en humanidades clásicas incluía el dominio de ambas lenguas.

El manuscrito HC 380/89 de la Hispanic Society of America representa otro testimonio excepcional. No se trata de una copia independiente del Setenario, como se ha sugerido ${ }^{63}$, sino más bien de una larga cita incluida en un estudio de Marcos Andrés Burriel: las Memorias para la vida del santo rey Don Fernando $^{64}$. El Setenario ocupa los folios 9r. a 29r. del mismo ejemplar. Burriel dedicó este volumen a Fernando VI. La hoja inicial, añadida al manuscrito posteriormente al trabajo de reproducción del texto, tal como lo evidencian sus pliegues, fue realizada por Francisco Javier Santiago y Palomares. El calígrafo

63 Fernando Gómez Redondo y José Manuel Lucía Megías, «Setenario» in Carlos Alvar y José Manuel Lucía Megías, Diccionario filológico de literatura medieval española. Textos y transmisión, Madrid, Castalia, 2002 , pág. 6 .

64 Se puede comprobar, consultando por ejemplo Andrés Marcos Burriel, Memorias para la vida del santo rey Don Fernando III dadas á luz con apéndices y otras ilustraciones por Don Miguel de Manuel Rodríguez, Madrid, Imprenta de la viuda de don Joaquín Ibarra, 1800, II, cap. LXVI, págs. 216-223. 
solía reproducir un único folio de los manuscritos originales para integrarlos en las copias realizadas por la Comisión de Archivos ${ }^{65}$. En el caso del Setenario, imitó la «letra de albalaes» del manuscrito 43-20 del Archivo Capitular de Toledo. Este ejemplar demuestra la voluntad de los ilustrados de apropiarse hasta de la maestría caligráfica de los hombres de la Edad Media.

Burriel fue el primero en interesarse por este texto en sus estudios, especialmente en las Memorias. Rápidamente, sus trabajos encontraron un eco en las diversas historias de la literatura y del derecho hispánicos, aunque no fue hasta el siglo XIX cuando el Setenario se convirtió en un objeto de estudio privilegiado, cuya naturaleza, estructura y datación se debatieron ${ }^{66}$. Esta primera aproximación al texto era todavía dependiente de su inclusión en un corpus de límites inciertos, de textos preeminentes y de interpretaciones sesgadas). A través de las lecturas, completas o fragmentarias, a menudo orientadas, y a través de su inclusión en catálogos sinópticos e historias de la literatura o del derecho, los ilustrados propusieron una primera caracterización del Setenario, que influyó de forma duradera en su aprehensión ulterior. La recepción dieciochesca de este texto nos parece reveladora del proceso de asimilación de los saberes a partir de datos preexistentes y de tradiciones historiográficas que empezaron tímidamente a renovarse.

\section{A guisa de conclusión: primicias}

Durante el siglo XVIII, el estudio del corpus alfonsí estaba todavía lastrado por varios mitos y presupuestos, así como de un contexto político-legal particular. La configuración de este campo de estudios se llevó a cabo entre necesidad y contingencia. Necesidad, porque la situación política de España implicaba una vuelta a los antiguos textos de derecho. Había que defender los intereses de la corona frente a las injerencias del papado. Grandes proyectos de inventario y examen de la documentación eclesiástica animaron a las instituciones, entre ellas la Real Academia de la Historia, a revisar la empresa intelectual del monarca. El conocimiento de Alfonso X y de su obra se convirtió progresivamente en un saber institucionalizado, que reemplazó las iniciativas individuales del si-

65 «Between 1752 and 1755 Burriel's team produced numerous volumes of collations, commentaries, and transcriptions from medieval liturgical manuscripts, many accompanied by single-page copies that Palomares drew to illustrate pages from the originals.», Boynton, Silent Music, pág. xix.

${ }_{66}$ Para una bibliografía completa de los estudios referentes al Setenario en el siglo XVIII y XIX, véase Kenneth H. Vanderford (ed.), Alfonso X el Sabio, Setenario, Barcelona: Editorial Crítica, 1984², págs. LXXVIII-LXXX. 
glo anterior. Si bien fueron pocos los intelectuales que se interesaron realmente por esta obra, su pertenencia a redes de saber oficiales favoreció la difusión del material alfonsí, así como su paulatina vulgarización. Los trabajos históricos, jurídicos y filológicos llevados a cabo a lo largo del siglo XVIII transformaron este corpus, así como la visión que de él se tenía. Sin embargo, no se puede negar la preeminencia absoluta de las obras jurídicas, y más particularmente de las Siete Partidas, en el proceso de reafirmación del poder y del derecho reales que caracterizan el periodo estudiado, y por consiguiente, el campo de los nacientes estudios alfonsíes. Ni los textos poéticos, ni las crónicas, ni los textos astronómicos, cuyos títulos y autorías seguían planteando problemas, gozaban de tanto prestigio y autoridad. El panorama descriptivo que hemos propuesto habrá de completarse con estudios de detalle que examinen los usos particulares de la legislación del Rey Sabio. Para ello, parece indispensable retomar la cronología de los cuerpos legales de referencia.

Contingencia, porque la búsqueda de textos judiciales permitió exhumar verdaderas joyas manuscritas atesoradas en las bibliotecas eclesiásticas del reino. Los intelectuales del siglo XVIII propusieron un panorama más completo de la obra del soberano y anticiparon, sin saberlo, varios siglos de estudios sobre el tema. Restablecieron verdades históricas, al tener acceso a fuentes y documentos más numerosos, pero también empezaron a difundir informaciones y opiniones erróneas que tienen todavía cierto impacto sobre nuestra aprehensión del corpus atribuido a Alfonso X. Deseosos de fomentar la historia e historiografía literaria de la nación española, no dudaron en alzar la figura del soberano como un emblema de las luces españolas. El rey se convirtió en un verdadero modelo para los intelectuales de la época en una relación especular. Las primicias en el campo de los estudios alfonsíes corresponden, en lo esencial, con los resultados de la empresa arqueológica llevada a cabo por la Comisión de Archivos. Al descubrir manuscritos olvidados, los miembros de este proyecto, figuras emblemáticas de las redes intelectuales de su época, crearon un retrato de Alfonso $\mathrm{X}$ que alcanzó una rápida difusión y cuyas características más destacadas siguen vigentes hoy en día. Este incipiente campo del saber se constituyó principalmente en torno a los fondos toledanos y escurialenses que determinaron las directrices de una cartografía de lo alfonsí, que dejaba al margen otros fondos de fuentes y manuscritos del Rey Sabio, por ejemplo, la Biblioteca Capitular de Sevilla. El siglo XVIII es, sin duda alguna, una época crucial para entender la obra de Alfonso X, aunque quede mucha investigación pendiente para aclarar el complejo proceso de rescate y evaluación inicial de su producción. 